\title{
GRID INTERCONNECTION OF PMSG BASED WIND ENERGY SYSTEM WITH POWER QUALITY IMPROVEMENT
}

\author{
${ }^{1}$ INDULEKHA K M, ${ }^{2}$ ELIZABETH P CHERIYAN \\ ${ }^{1}$ MTech Student NIT Calicut, \\ ${ }^{2}$ Associate Professor NIT Calicut \\ E-mail: ${ }^{1}$ k.mindulekha@gmail.com
}

\begin{abstract}
The Renewable Energy Sources (RES) are being increasingly used during recent years. The integration of RES to the grid introduces power quality issues at the distribution level. In addition to that, the use of linear/nonlinear unbalanced loads made power quality as one of the major issues faced by the electrical industry. In this paper a wind energy conversion system with power quality improvement features is described. Permanent Magnet Synchronous Generator (PMSG) based wind power generation system modeling is done. A control strategy for the grid interfacing inverter with hysteresis current control is developed to improve power quality. The grid interfacing inverter is controlled in such a manner that the combination of grid interfacing inverter along with linear/nonlinear unbalanced load appears as balanced linear load to the grid at PCC. Extensive simulation studies are carried out in Matlab/Simulink to validate the proposed control approach.
\end{abstract}

Index Terms-Distributed generation, Distribution system, Grid interconnection, Permanent magnet synchronous generator, Power quality, Renewable energy, Wind energy

\section{INTRODUCTION}

The use of renewable energy sources, such as solar, wind, etc is very old; they have been used since many centuries before our time and their applications continued throughout history and until the "industrial revolution", when they were abandoned due to the low price of petroleum[1]. During recent years, the world is reverting back to renewable energy sources due to the increase in fossil fuel prices and the environmental problems caused by the use of conventional fuel sources. Among the renewable power generators, solar and wind are the most promising energy sources and are being increasingly used[1]. Wind power alone already provides a significant share of electricity in many areas. In the near future the electric grid will include a large number of small energy producers by the integration of renewable energy sources such as solar panels or wind generators to the grid.

Power electronic technology plays an important role in the integration of renewable energy sources to the grid. When the power electronic converters are used it introduces a lot of harmonics in the system. On the other hand the increased use of power electronic equipments and nonlinear loads by the industries and the households together made the degradation of power quality as one of

the major problems in electric industry. The nonlinear load currents can create voltage harmonics and it may lead to serious power quality issues.

As a solution for these problems active power filters are extensively used to reduce harmonics and unbalance. In this paper the grid interfacing inverter is controlled such that active power filter functionality is incorporated into it. So an additional hardware cost for the active power filter can be eliminated and the maximum utilization of the grid interfacing inverter is possible which will be underutilized most time due to the intermittent nature of wind energy[2].

\section{WIND ENERGY SYSTEM}

\section{A. Basic System}

The block diagram representation of the permanent magnet synchronous generator based wind power generation system is shown in Fig. 1.

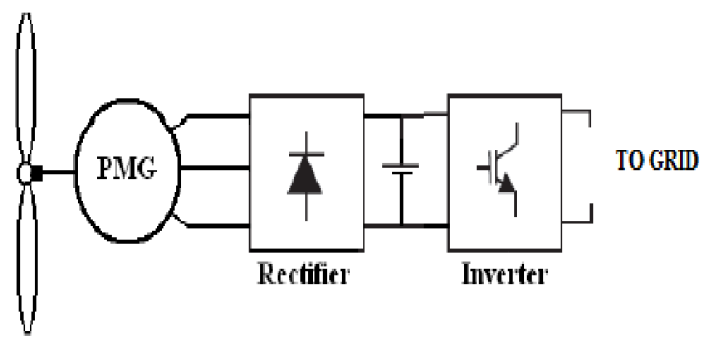

Wind Tubine

Fig. 1. Basic block diagram of wind energy conversion system

The wind turbine is the prime mover of the permanent magnet synchronous generator. Due to the non uniform nature of the wind speed, the output of permanent magnet generator will be fluctuating. The PMSG output has to be converted into DC before connecting to the DC link of the inverter

\section{B. Wind Model}

The basic wind model consists of four components[3]

$\mathrm{V}_{\text {wind }}=\mathrm{V}_{\mathrm{bw}}+\mathrm{V}_{\mathrm{gw}}+\mathrm{V}_{\mathrm{rm}}+\mathrm{V}_{\mathrm{nm}}$

where, $V_{b w}, V_{g w}, V_{r m}$, and $V_{n m}$ are the Base wind, Gust wind, Ramp wind and Noise wind components respectively in $\mathrm{m} / \mathrm{s}$. 


\section{Wind Turbine Model}

A wind turbine extracts kinetic energy from the wind to drive the wind turbine rotor, which is connected to a generator producing electricity. The maximum power output from the wind turbine is limited by the power coefficient $\mathrm{Cp}$ which is a function of the tip speed ratio $\lambda[4]$. The maximum value of $\mathrm{Cp}$ will be $59.3 \%$, the Betz Limit.

In general, value of $\mathrm{Cp}$ lies between $25 \%$ - 45\%. The power $(P t)$ extracted from the wind by a wind turbine rotor can be expressed as[4]:

$\mathrm{Pt}=0.5 \square \mathrm{Cp} \square \mathrm{R}^{2} \mathrm{v}^{3}$

where

$\mathrm{R}$ is the wind turbine rotor radius in $\mathrm{m}$

$\rho$ is the air density in $\mathrm{kg} / \mathrm{m}^{3}$

$\mathrm{v}$ is the wind speed $\mathrm{m} / \mathrm{s}$

The tip speed ratio can be expressed as: $\lambda=\mathrm{R} * \omega / \mathrm{v}$ where $\omega$ is the angular velocity of the wind turbine rotor in $\mathrm{rad} / \mathrm{s}[4]$.

The variation of the rectified output voltage of the permanent magnet synchronous generators with the wind speed is shown in Fig 2. As the wind speed decreases, the magnitude and frequency of the output voltage of the permanent magnet synchronous generator also decreases.
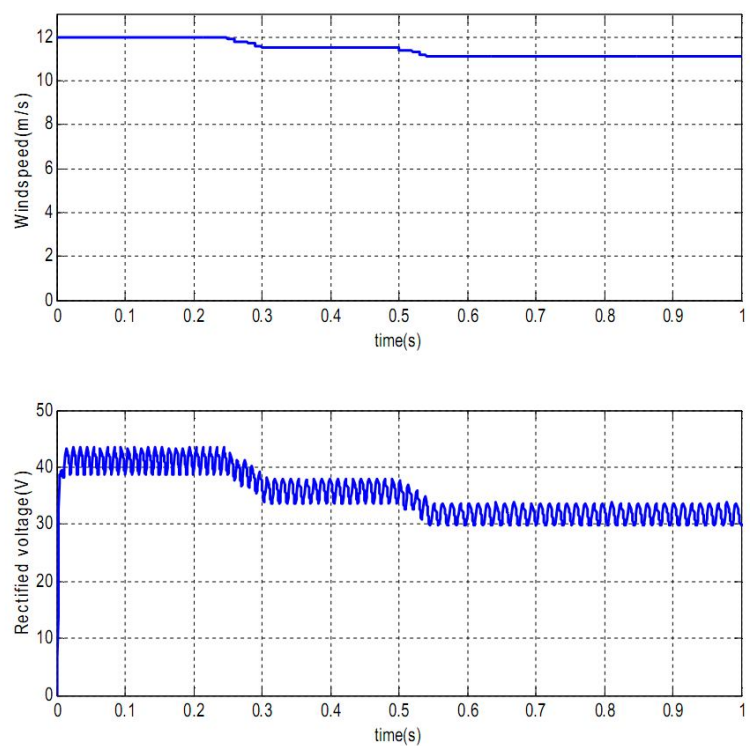

Fig. 2. Rectified voltage output of the PMSG generator with variation in wind speed

During the period 0.25-0.3 seconds and 0.5-0.55 seconds, gradual reduction in the wind speed is applied and correspondingly the voltage magnitude and frequency of the output voltage of the permanent magnet synchronous generator is decreased.

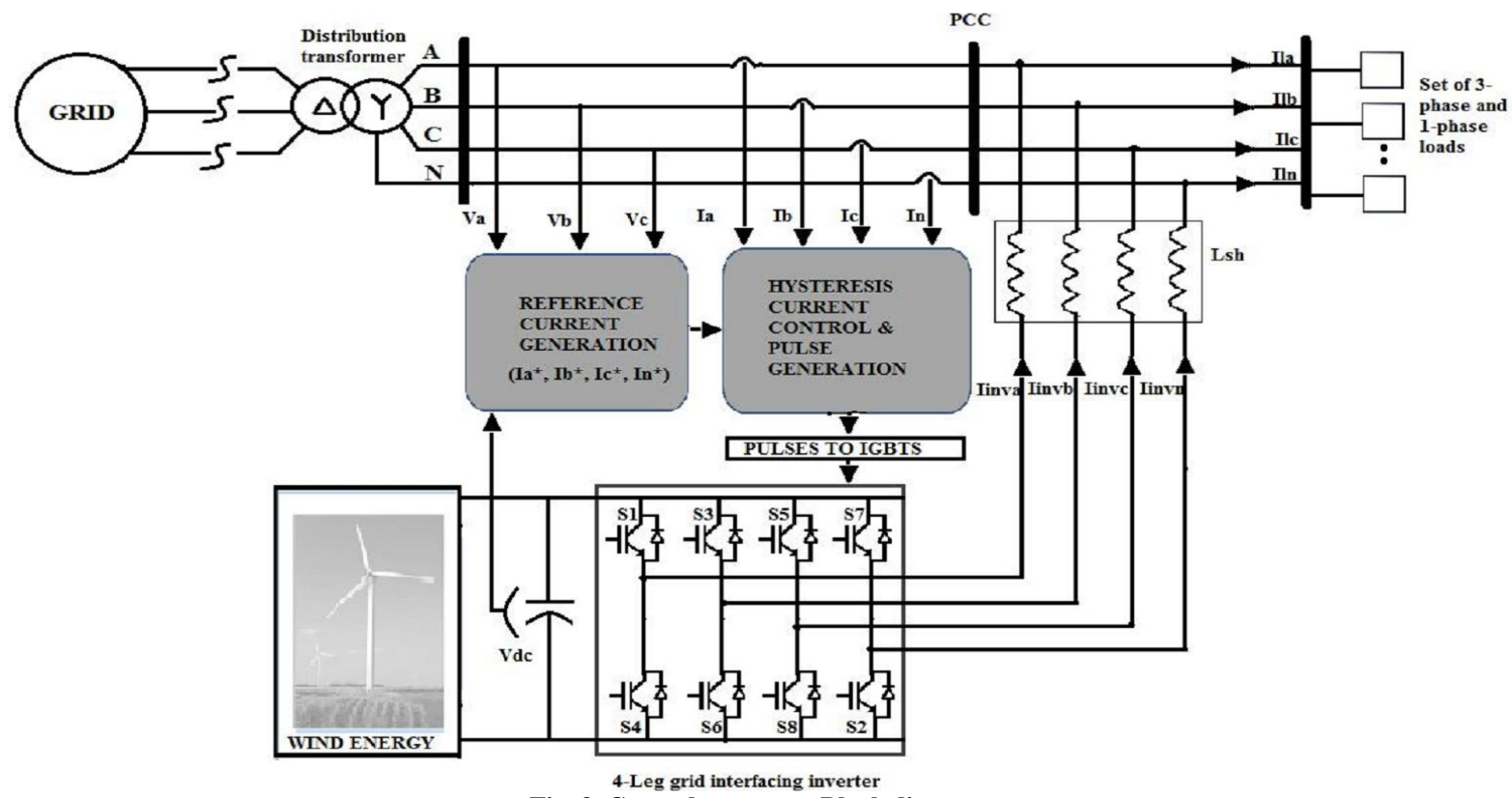

Fig. 3. Control strategy-Block diagram

\section{A. System Description}

The block diagram representation of the grid interfacing inverter with the incorporation of the control strategy is shown in Fig 3. The system consists of a 3 phase 4 wire distribution network which supplies a set of 3 phase and single phase linear/nonlinear unbalanced load. A 3 phase 4 wire grid interfacing inverter is used for integrating renewable energy source to the grid. Due to the intermittent nature of wind energy, the generated power is of variable nature.
The output from wind energy system is connected at the dc link of the inverter. The output from the wind energy system should be conditioned in such a manner that a ripple free DC voltage appears at the DC link of the inverter. Inverter is connected to the grid by means of coupling inductor. The grid interfacing inverter also acts as shunt active power filter which reduces the harmonics in the system. The fourth leg of the inverter is for neutral current compensation which reduces the magnitude of the neutral current to zero. 
The dc-link plays an important role in transferring this variable power from the wind energy system to the grid[2]. Wind energy source is represented as current source connected to the dc-link of a grid-interfacing inverter. Fig 4 shows the systematic representation of power transfer from the wind energy system to the grid via the dc-link.

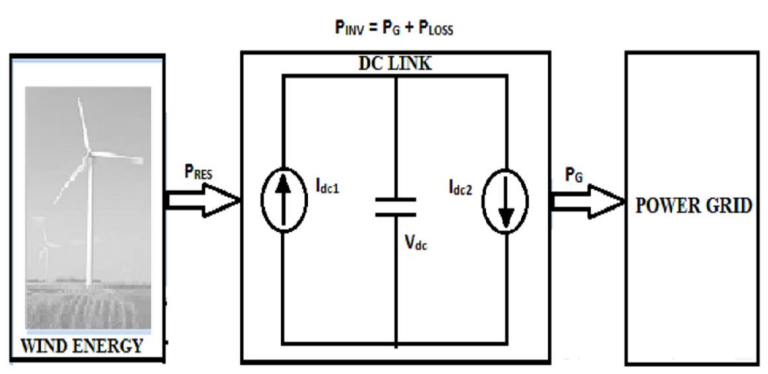

Fig. 4.DC link equivalent diagram

The current injected by wind energy system into dc-link at voltage level $\mathrm{V}_{\mathrm{dc}}$ can be given as

$$
\mathrm{I}_{\mathrm{dc} 1}=\mathrm{P}_{\mathrm{RES}} / \mathrm{V}_{\mathrm{dc}}
$$

where $P_{\text {RES }}$ is the power generated from RES.

The current flow on the other side of dc-link can be represented as,

$$
\mathrm{I}_{\mathrm{dc} 2}=\mathrm{P}_{\mathrm{INV}} / \mathrm{V}_{\mathrm{dc}}=\left(\mathrm{P}_{\mathrm{G}}+\mathrm{P}_{\mathrm{LOSS}}\right) / \mathrm{V}_{\mathrm{dc}}
$$

where $\mathrm{P}_{\mathrm{INV}}, \mathrm{P}_{\mathrm{G}}$ and $\mathrm{P}_{\mathrm{LOSS}}$ and are total power available at grid-interfacing inverter side, active power supplied to the grid and inverter losses respectively[2].

\section{B. Control Strategy for Grid Interfacing Inverter}

Hysteresis current control method is used for the control of grid interfacing inverter. The main objective of this control approach is to regulate the power at PCC during variable output power conditions from the wind energy system.

The regulation of dc link voltage is carried out by means of a PI controller. The actual dc link voltage is compared with the reference value and the difference between actual and reference value (error) is given as the input to PI controller. The output of the PI controller is an active current component $\mathrm{I}_{\mathrm{m}}$. This active current component is used for the generation of grid reference currents. The active current component $I_{m}$ is multiplied with unity grid voltage vector for the generation of reference currents. The grid synchronizing angle $\square \square \square$ can be obtained from Phase Locked Loop (PLL) which will be used to generate unity vector template as follows[2] .

$U_{a}=\sin (\theta)$

$U_{b}=\sin (\theta-2 \pi / 3)$

$U_{c}=\sin (\theta+2 \pi / 3)$

The inverter is controlled such that the grid current is always maintained as balanced sinusoidal at upf. The fourth leg of the inverter is used for the neutral current compensation. The reference for neutral current is set as zero. By the implementation of the proposed control approach the inverter will be able to provide harmonic compensation, reactive power compensation, neutral current compensation and will be able to reduce unbalance.

The input to the PI controller can be represented as

$V_{\text {dcerr }}(n)=V^{*}{ }_{d c}(n)-V_{d c}(n)$

The output of discrete-PI regulator at the $n^{\text {th }}$ sampling instant is expressed as

$I_{m(n)}=I_{m(n-1)}+K_{p}\left(V_{\text {dcerr }}(n)-V_{\text {dcerr }}(n-1)+K_{l} V_{\text {dcerr }}(n)\right.$

The instantaneous values of reference three phase grid currents are computed as

$$
\begin{aligned}
& \mathrm{I}_{\mathrm{a}}^{*}=\mathrm{I}_{\mathrm{m}} * U_{\mathrm{a}} \\
& \mathrm{I}_{\mathrm{b}}^{*}=I_{\mathrm{m}} * U_{\mathrm{b}} \\
& \mathrm{I}_{\mathrm{c}}{ }^{*}=I_{\mathrm{m}} * U_{\mathrm{c}} \\
& \mathrm{I}_{\mathrm{n}}{ }^{*}=0
\end{aligned}
$$

The reference grid currents $\left(\mathrm{Ia}^{*}, \mathrm{Ib}^{*}, \mathrm{Ic}^{*}\right.$ and $\left.\mathrm{In} *\right)$ are compared with actual grid currents ( Ia, Ib, Ic and In ) to compute the current errors as

$$
\begin{aligned}
& I_{\text {aerr }}=I_{a}{ }^{*}-I_{a} \\
& I_{\text {berr }}=I_{b} *-I_{b} \\
& I_{\text {cerr }}=I_{c}{ }^{*} I_{c} \\
& I_{\text {nerr }}=I_{n}{ }^{*} I_{n}
\end{aligned}
$$

These current errors are given to hysteresis current controller. The hysteresis controller generates the switching pulses $\left(\mathrm{P}_{1}\right.$ to $\left.\mathrm{P}_{8}\right)$ for the gate drives of grid-interfacing inverter, based on the current errors and hysteresis bandwidth setting.

The average model of 4-leg inverter is obtained by the following state space equation

$$
\begin{aligned}
& \begin{array}{l}
\frac{d I n w a}{d t}=\frac{V_{l w a}-V_{a}}{L_{s h}} \\
\frac{d I_{\text {lnw }}}{d t}=\frac{V_{l n w s}-V_{b}}{L_{s h}}
\end{array} \\
& \frac{d L_{\text {Inw }}}{d t}=\frac{V_{\text {Lwve }}-V_{s}}{L_{s h}}
\end{aligned}
$$

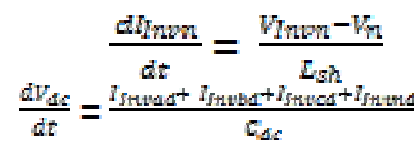

where $\mathrm{V}_{\text {Inva }}, \mathrm{V}_{\text {Invb }}, \mathrm{V}_{\text {Invc }}$ and $\mathrm{V}_{\text {Invn }}$ are the three-phase ac switching voltages generated on the output terminal of the grid interfacing inverter. These output terminal voltages can be modeled in terms of instantaneous dc bus voltage and switching pulses of the inverter as

$$
\begin{aligned}
& \mathrm{V}_{\text {Inva }}=\left(\mathrm{P}_{1}-\mathrm{P}_{4}\right) \mathrm{V}_{\mathrm{dd}} / 2 \\
& \mathrm{~V}_{\text {Invb }}=\left(\mathrm{P}_{3}-\mathrm{P}_{6}\right) \mathrm{V}_{\mathrm{dc}} / 2 \\
& \mathrm{~V}_{\text {Invc }}=\left(\mathrm{P}_{5}-\mathrm{P}_{2}\right) \mathrm{V}_{\mathrm{dc}} / 2 \\
& \mathrm{~V}_{\text {Invn }}=\left(\mathrm{P}_{7}-\mathrm{P}_{8}\right) \mathrm{V}_{\mathrm{dc}} / 2
\end{aligned}
$$

Similarly the charging currents $\mathrm{I}_{\text {Invadc }}, \mathrm{I}_{\text {Invbdc }}, \mathrm{I}_{\text {Invcdc }}$ and $\mathrm{I}_{\text {Invndc }}$ on dc bus due to the each leg of inverter can be expressed as 


$$
\begin{array}{ll}
\mathrm{I}_{\text {Invade }} & =\mathrm{I}_{\text {Inva }}\left(\mathrm{P}_{1}-\mathrm{P}_{4}\right) \\
\mathrm{I}_{\text {Invbde }} & =\mathrm{I}_{\text {Invb }}\left(\mathrm{P}_{3}-\mathrm{P}_{6}\right) \\
\mathrm{I}_{\text {Invedc }} & =\mathrm{I}_{\text {Inve }}\left(\mathrm{P}_{5}-\mathrm{P}_{2}\right) \\
\mathrm{I}_{\text {Invnde }} & =\mathrm{I}_{\text {Invn }}\left(\mathrm{P}_{7}-\mathrm{P}_{8}\right)
\end{array}
$$

Permanent magnet synchronous generator based wind energy system with variable wind speed is connected on the dc-link of grid-interfacing inverter. An unbalanced 3-phase 4-wire nonlinear load, whose unbalance, harmonics, and reactive power need to be compensated, is connected at the Point of Common Coupling (PCC). The waveforms of grid voltage, grid currents, unbalanced load current, inverter currents, the corresponding active-reactive powers of grid, load and inverter are shown in figures 5-7. Positive values of grid active-reactive powers and inverter active-reactive powers imply that these powers flow from grid side towards PCC and from inverter towards $\mathrm{PCC}$, respectively. The active and reactive powers absorbed by the load are denoted by positive signs.

DC link voltage is maintained at constant value in order to facilitate the active and reactive power flow. During the period, $\mathrm{t}=0.5 \mathrm{~s}$ to $\mathrm{t}=0.75 \mathrm{~s}$ the wind speed is kept at $\mathrm{t}=12 \mathrm{~m} / \mathrm{s}$. At $\mathrm{t}=0.75 \mathrm{~s}$ wind speed is decreased to $11.5 \mathrm{~m} / \mathrm{s}$. As the wind speed changes the active power contribution from the RES decreases, and hence the power which is getting fedback to the grid decreases. The reactive power supplied from the grid side is always zero, the load reactive power demand is completely supplied from the inverter side. From the grid current waveform (Fig. (5b)) it is clear that by the proper switching control of the inverter neutral current compensation is also be achieved.

The THD analysis of grid current waveform after the compensation is given in figures 8-10. The THD of the phase $\mathrm{a}$, phase $\mathrm{b}$ and phase $\mathrm{c}$ grid currents are reduced from $13 \%, 14 \%$, and $13 \%$ to $0.95 \% 0.94 \%$ and $0.91 \%$ respectively which will satisfy the IEEE standard for the grid interconnection $(<5 \%)$.
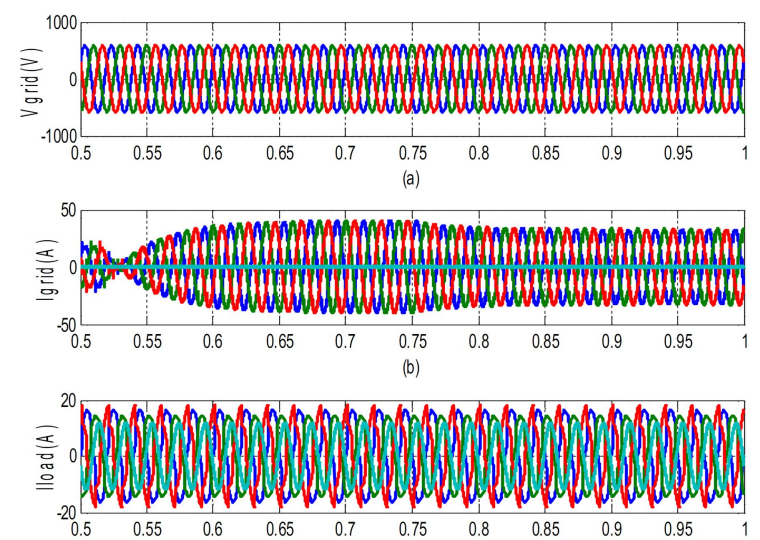

$$
\text { (c) }
$$

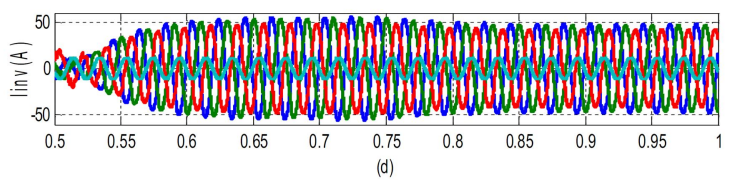

Fig. 5(a).Grid voltage, 5(b).Injected Grid current, 5(c).Load urrent, 5(d).Inverter current
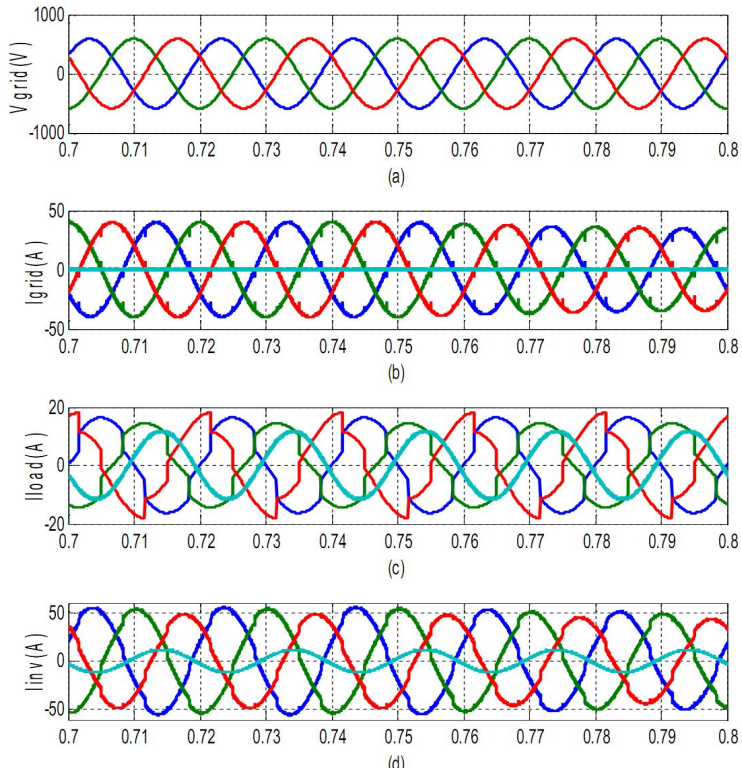

Fig.6. Expanded view: (a)Grid voltage, (b)Injected Grid current (c)Loadcurrent, (d)Inverter current
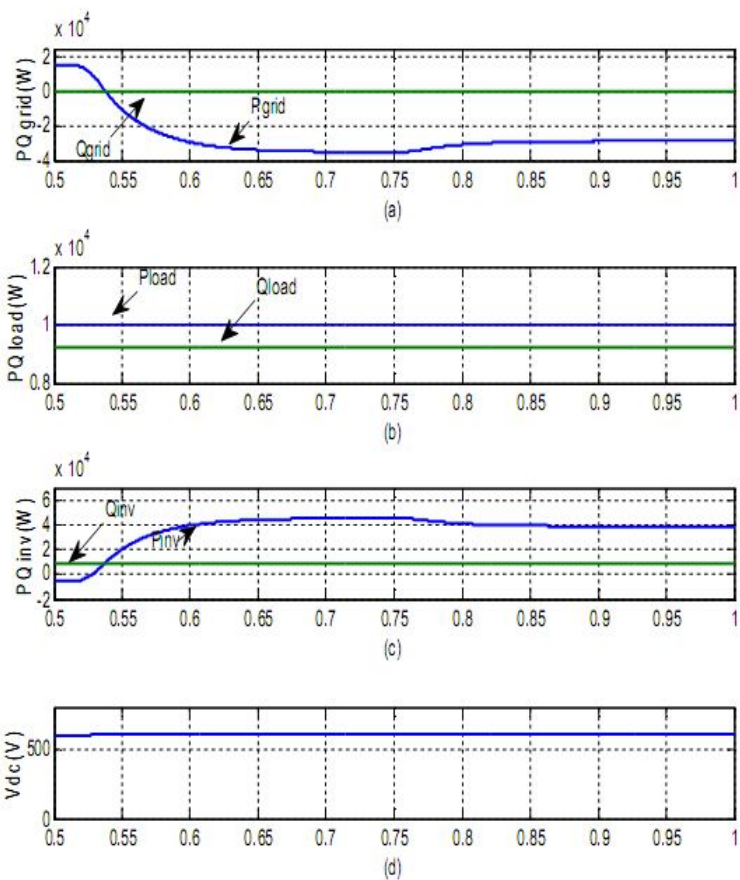

Fig. 7.(a)Injected Grid power, 7(b)Load power, 7(c)Inverter power, 7(d)DC Link voltage

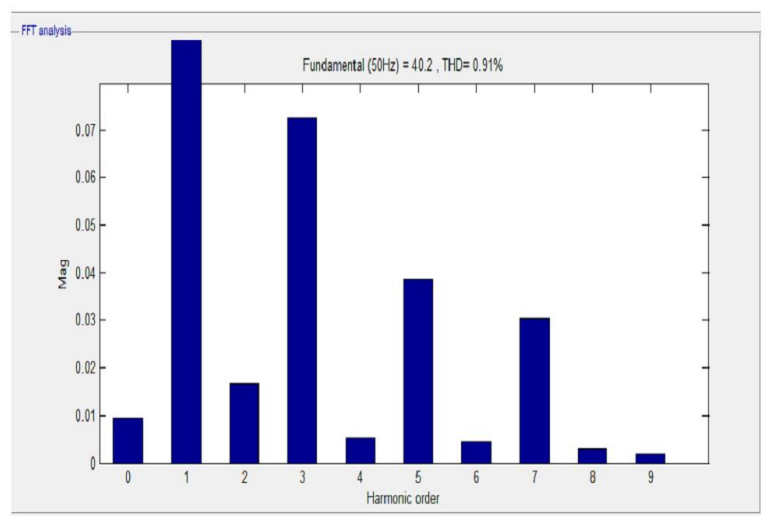

Fig. 8.FFT Analysis-Grid current - phase a 


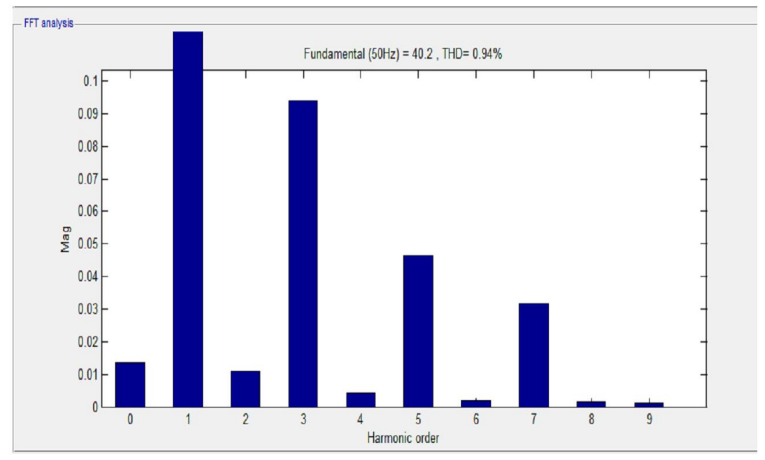

Fig. 9.FFT Analysis-Grid current - phase b

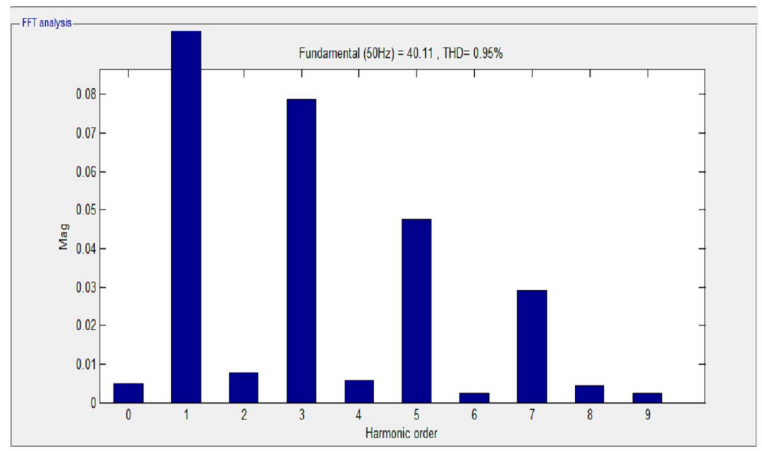

Fig. 10.FFT Analysis-Grid current - phase c

Thus from the simulation results, it is clear that the grid-interfacing inverter can be effectively used for the compensation of the load reactive power, current unbalance and current harmonics in addition to active power transfer from the wind energy system. This enables the grid to supply/ receive sinusoidal and balanced power at UPF.

\section{CONCLUSION}

This paper has presented a permanent magnet synchronous generator based wind energy system with power quality improvement. A control strategy based on hysteresis current control is developed for the grid interfacing inverter to mitigate power quality issues. Simulink modeling is done and the model is simulated for varying power output from the renewable energy source. By the use of designed control strategy, the interfacing inverter is able to work as an active power filter along with transferring power from wind energy system to the grid. From the result it is evident that by the implementation of control strategy, inverter is able to perform the following functions.

1) Reactive power compensation

2) Neutral current compensation

3) Harmonic compensation

4) Reduction in unbalance

Therefore the need of shunt active power filter can be eliminated and the additional hardware cost can be minimized.

\section{REFERENCES}

[1] http://www.solener.com/intro_e.html

[2] Mukhtiar Singh, Vinod Khadkikar, Ambrish Chandra and Rajiv $\mathrm{K}$ Varma, "Grid interconnection of renewable energy sources at the distribution level with power quality improvement features," IEEE Trans on Power Delivery, Vol. 26, No 1, Jan 2011

[3] Z Chen, E Spooner, "Grid power quality with variable speed wind turbines," IEEE Trans on Energy conversion, Vol. 16, No 2, June 2001.

[4] Z Chen, E Spooner, "Grid interface options for variable speed permanent magnet generators", IEE Proc. Electr. Power Appl., Vol. 145, No 4, July 1998

[5] Manish Kumar Yadav,Amrish Kumar Upadhayay, "Power flow control of permanent magnet synchronous generator based wind energy conversion system with DC - DC converter and voltage source inverter," IJEEE, Vol. 7,no 8, 2014.

[6] Gidwani Lata and H P Tiwari, "Improving power quality of wind energy conversion system with harmonic filters," Proc. International multiconference of engineers and computer scientists, Vol. 2, Mar 2011

[7] Seung- Ho Song, Shin-il Kang and Nyeon-Kun Hahm, "Implementation and control of grid connected AC-DC-AC power converter for variable speed wind energy conversion system," Applied power electronics conference and exposition, 2003 APEC'03, $18^{\text {th }}$ annual IEEE, Vol.1

[8] J. P. Pinto, R. Pregitzer, L. F. C. Monteiro, and J. L. Afonso, "3-phase 4-wire shunt active power filter with renewable energy interface," presented at the Conf. IEEE Rnewable Energy \& Power Quality, Seville, Spain, 2007.

[9] Maur'icio Aredes, J"urgen H"afner, and Klemens Heumann, "Three-Phase Four-Wire Shunt Active Filter Control Strategies," IEEE Trans. Power Electron, vol.12, no.2, March 1997

[10] B. Shyam, Aswathy B. Raj , Robins Anto , "A Novel Wind Energy Conversion System with Power Quality Improvement Features," IEEE PES Innovative Smart Grid Technologies India 2011 